\title{
Protein versus DNA as a marker for peripheral blood mononuclear cell counting
}

\author{
Robert S. Jansen • Hilde Rosing • Jan H. M. Schellens • \\ Jos H. Beijnen
}

Received: 28 May 2009/Revised: 23 July 2009 / Accepted: 29 July 2009 /Published online: 16 August 2009

(C) The Author(s) 2009. This article is published with open access at Springerlink.com

\begin{abstract}
Quantitative analysis of intracellular analytes requires an accurate and precise assay not only for the quantitation of the analytes, but also for the quantitation of the number of cells in which they were determined. In this technical note we compare protein and DNA as markers for the number of peripheral blood mononuclear cells (PBMCs) isolated from whole blood. The protein content of samples was highly influenced by red blood cell contamination and was, therefore, a less suitable marker. The DNA-based method was unaffected by red blood cell contamination and was finally validated over a range from $10 \times 10^{6}$ to $300 \times 10^{6} \mathrm{PBMCs} / \mathrm{mL}$.
\end{abstract}

Keywords Bioanalytical methods .

Nucleic acids (DNA | RNA) · Cell counting · Hoechst 33258

\section{Introduction}

The molecular targets of many drugs are not located in blood plasma or the exterior of cells, but rather inside

R. S. Jansen $(\bowtie) \cdot H$. Rosing $\cdot$ J. H. Beijnen

Department of Pharmacy \& Pharmacology,

Slotervaart Hospital/The Netherlands Cancer Institute,

Louwesweg 6,

1066 EC Amsterdam, The Netherlands

e-mail: robert.jansen@slz.nl

J. H. M. Schellens

Division of Medical Oncology, The Netherlands Cancer Institute,

1066EC Amsterdam, The Netherlands

J. H. M. Schellens $\cdot$ J. H. Beijnen

Science Faculty, Department of Pharmaceutical Sciences,

Utrecht University,

3584CA Utrecht, The Netherlands cells. Plasma levels of these compounds can therefore be regarded only as a surrogate for the actual intracellular concentrations. Still, determination of plasma levels appears sufficient for most drugs because an equilibrium exists between the plasma and the intracellular drug concentration.

For some drugs and metabolites, however, the plasma concentrations are not in equilibrium with intracellular concentrations. This can be due to intracellular accumulation of the drug, or due to intracellular formation of metabolites.

The active metabolites of nucleoside analogues, which are used in anticancer, antiviral and immunosuppressive therapies, are only formed inside cells, and have a half-life that is much longer than that of their parent nucleoside in plasma. For these drugs, intracellular metabolite levels are much more informative than plasma prodrug levels [1].

Most assays for intracellular analytes use peripheral blood mononuclear cells (PBMCs) as a matrix because of their role in the immune system and because their nucleoside metabolism is fully functional, as opposed to that of red blood cells and platelets.

Intracellular assays require an accurate and precise determination of the amount of analyte as well as of the number of cells in which it was determined. Many publications have described extensive validations of intracellular assays, but these validations generally do not include the cell counting step [2,3]. Moreover, separate validations of cell counting procedures are very sparse [4]. The cell counting step can, however, be a considerable source of variability [5].

Since the accuracy and precision of the final result is composed of the accuracy and precision of the cell count and the final analysis, an accurate and precise cell counting method is pivotal to obtain correct results. PBMCs have 
been counted using a microscope, haemocytometer and protein determinations $[2,6,7]$. More recently, Benech et al. [4] showed the positive relationship between the number of PBMCs and DNA content. Using the intercalating agent SYBR green, they developed and validated a DNA-based PBMC counting method.

Here, we compare the Bradford protein determination [8] with a DNA determination using the fluorescent dye Hoechst 33258 [9] for counting the number of PBMCs in a sample. Moreover, we describe the validation of a DNAbased PBMC counting method.

\section{Experimental}

\section{Cell isolation and preparation}

Red blood cells were obtained by centrifuging whole blood for $5 \mathrm{~min}$ at $1,500 \mathrm{~g}$ and collecting the precipitate. The cells were frozen, and the haemoglobin concentration was determined using a haematology analyser (Cell-Dyn 4000; Abbott Diagnostics, Abbott Park, IL, USA).

For comparison of cell counting with a haemocytometer, the protein determination and the DNA determinations, $8 \mathrm{~mL}$ whole blood was collected in cell preparation tubes which contain a Ficoll density gradient (BD Vacutainer CPT; BD, Franklin Lakes, NJ, USA). After centrifugation (20 min at 1,500 g), the PBMCs were collected and washed with $15 \mathrm{~mL}$ phosphate-buffered saline (PBS). The cells were finally resuspended in $70 \mu \mathrm{L}$ PBS.

For the validation of the DNA-based cell counting assay, PBMCs were isolated from human leucocyte buffy coat (Sanquin, Amsterdam, The Netherlands) originating from $500 \mathrm{~mL}$ whole blood, as previously described [7]. This method also uses a Ficoll density gradient, but is adapted for the isolation of larger numbers of PBMCs. The PBMC suspensions obtained were diluted to the desired concentration with PBS, aliquoted in $10-\mu \mathrm{L}$ volumes and stored at $-70{ }^{\circ} \mathrm{C}$.

Cell count using a haemocytometer

The number of PBMCs and red blood cells was determined in each sample using a Cell-Dyn 4000 haematology analyser.

Protein determination

The total protein concentration in samples was determined using the Bradford protein assay (Bio-Rad protein assay; Bio-Rad, Hercules, CA, USA). Seven bovine serum albumin calibration standards were prepared in concentrations ranging from 50 to $1,000 \mu \mathrm{g} / \mathrm{mL}$. Calibration standards and unknowns were transferred $(10 \mu \mathrm{L})$ to a $96-$ well microplate (BD microtest ${ }^{\mathrm{TM}}$, flat bottom; BD, Franklin Lakes, NJ, USA). All samples were processed in duplicate. After the addition of $250 \mu \mathrm{L}$ dye reagent (Coomassie brilliant blue G-250), the absorption was directly measured at $590 \mathrm{~nm}$ using a microplate reader (EL340; Bio-Tek Instruments, Winooski, VT, USA).

\section{DNA-based cell count}

The DNA-based cell counting was performed using the fluorescent dye Hoechst 33258 (Bio-Rad DNA quantitation kit; Bio-Rad, Hercules, CA, USA). Seven PBMC calibration standards were prepared in concentrations ranging from $10 \times 10^{6}$ to $300 \times 10^{6} \mathrm{PBMCs} / \mathrm{mL}$ (determined using a haemocytometer). Moreover, validation PBMC suspensions were prepared from a second donor buffy coat at concentrations of approximately $10 \times 10^{6}, 75 \times 10^{6}$ and $250 \times 10^{6}$ $\mathrm{PBMCs} / \mathrm{mL}$ (determined using a haemocytometer). Calibration standards, validation samples and unknowns in PBS (all $10 \mu \mathrm{L}$ ) were diluted with $750 \mu \mathrm{L}$ water and sonicated for $30 \mathrm{~min}$. A $10-\mu \mathrm{L}$ volume of this suspension was then transferred to a 96-well opaque microplate (Optiplate-96 F; PerkinElmer, Waltham, MA, USA) in duplicate. After the addition of $300 \mu \mathrm{L}$ dye [ $2 \mu \mathrm{g} / \mathrm{mL}$ Hoechst 33258 in assay buffer-2 M NaCl, $100 \mathrm{mM}$ EDTA, $100 \mathrm{mM}$ tris(hydroxymethyl)aminomethane], the microplate was measured five times within $0.1 \mathrm{~s}$ with excitation at $355 \mathrm{~nm}$ and emission at $460 \mathrm{~nm}$ using a Wallac Victor 1420 (PerkinElmer, Waltham, MA, USA). The mean of the five measurements was used for the data processing.

\section{Data processing}

Calibration curves were constructed using the Excel 2003 software program (Microsoft, Redmond, WA, USA). For the protein determination, we used a quadratic fit with $1 / x^{2}$ weighting, because absorption is not linear over the concentration range. For the DNA-based cell count, we used a linear fit with $1 / x^{2}$ weighting. Calibration standards were excluded if the deviation of the back-calculated concentration from the nominal concentration was more than $\pm 15.0 \%$ or more than $\pm 20.0 \%$ at the lower limit of quantification (LLOQ). No more than $25 \%$ of the calibration standards were allowed to be rejected from the calibration curve, which should contain at least one sample at the LLOQ and the upper limit of quantification. Samples were only reported if the results from the duplicate analyses did not deviate more than $15 \%$.

Method comparison

Whole blood was collected from four individuals and PBMCs were isolated as described in "Cell isolation and 
preparation". Of the final cell suspension, $20-\mu \mathrm{L}$ aliquots were diluted 20-fold in PBS (haemocytometer) and water (protein determination), or 76-fold in water (DNA determination). The samples were repeatedly measured using each method.

Validation of DNA method

\section{Linearity}

Deviations of the back-calculated concentrations from the nominal concentrations should be within \pm 20 at the LLOQ and within $\pm 15 \%$ at the other levels. No more than one third of the calibration standards were allowed to be rejected from the calibration curve.

\section{Inaccuracy and precision}

The intra- and interassay inaccuracy and precision were determined by analysing the validation samples at three levels in three separate runs ( $N=5$ per run). The inaccuracy of the method was assessed by comparing the determined cell count (DNA-based determination) with the reference cell count (haemocytometer). The coefficients of variation were calculated to assess the precision of the method. Inaccuracies and precisions should be within $\pm 15 \%$ and less than $15 \%$, respectively, except at the LLOQ, where they should be within $\pm 20 \%$ and less than $20 \%$, respectively.

\section{Stability}

The stability of the PBMC suspensions was assessed threefold with samples containing $67.5 \times 10^{6} \mathrm{PBMCs} / \mathrm{mL}$. The stability of non-lysed samples in PBS was assessed after $7 \mathrm{~h}$ at ambient temperatures, and after two freeze

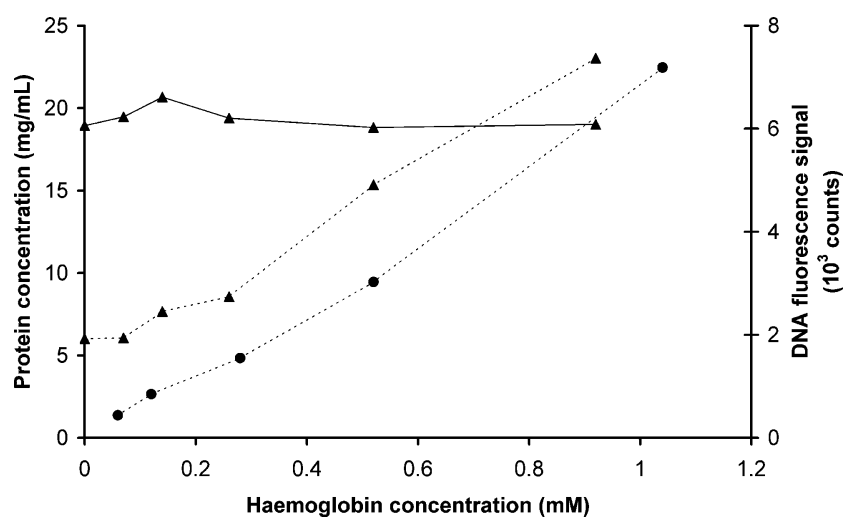

Fig. 1 Effect of the haemoglobin concentration on the protein (dashed line) and the DNA (solid line) concentration in samples with peripheral blood mononuclear cells (PBMCs) (triangles) and without PBMCs (circles)

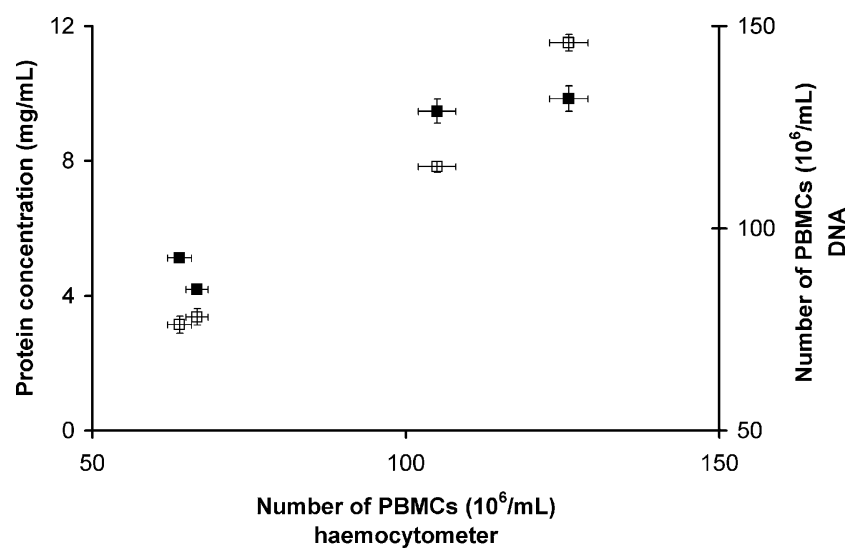

Fig. 2 Protein concentration (closed squares) and DNA-based PBMC count (open squares) versus cell count obtained using a haemocytometer. Data points are presented as the mean $(N=5$ for protein determination and DNA-based cell count, $N=3$ for haemocytometer cell count) \pm the standard error of the mean

$\left(-70^{\circ} \mathrm{C}\right)$-thaw cycles. Likewise, the stability was tested in lysed samples after $2 \mathrm{~h}$ at $20-25^{\circ} \mathrm{C}$, and after two freeze $\left(-70^{\circ} \mathrm{C}\right)$-thaw cycles. Moreover, the reassay reproducibility was assessed after storing a microplate for $4.5 \mathrm{~h}$ at ambient temperatures, protected from light. The samples were considered stable if the concentrations found did not deviate by more than $15 \%$ from the nominal or initial concentration.

\section{Results and discussion}

In studies where we used the Bradford protein assay to correct for the number of cells isolated from clinical samples, a small number of samples contained exceptionally high protein levels. Visual inspection of these samples revealed a red discoloration. We reasoned that red blood cell contamination was the source of the high protein levels observed. Because red blood cells do not contain DNA, a DNA-based cell counting method was considered.

In preliminary experiments we investigated this possibly confounding factor more thoroughly by spiking neat solutions (without PBMCs) and PBMC-containing samples with red blood cells. Figure 1 clearly shows the impact that haemoglobin, a marker for red blood cell contamination, has on the amount of protein in a sample. Even a relatively low contamination had a significant influence on the total protein concentration. A red blood cell lysis and wash step would improve the performance of the protein method, but requires extra sample handling. The DNA signals were, as expected, not influenced by the red blood cell contamination, making the DNA-based cell counting method more robust towards the inevitable red blood cell contamination. Therefore, the DNA-based cell counting was developed further. 
Table 1 Assay performance of the DNA-based peripheral blood mononuclear cell $(P B M C)$ counting method. Samples containing PBMCs at three concentrations were analysed fivefold in three separate analytical runs

\begin{tabular}{|c|c|c|c|c|}
\hline \multirow[t]{2}{*}{ Run } & \multirow[t]{2}{*}{ Replicate } & \multicolumn{3}{|c|}{ PBMC concentration $\left(10^{6} / \mathrm{mL}\right)$} \\
\hline & & 14.2 & 67.5 & 245 \\
\hline \multirow[t]{5}{*}{1} & 1 & 18.2 & 82.5 & 243 \\
\hline & 2 & 17.0 & 76.8 & 232 \\
\hline & 3 & 15.5 & 77.3 & 233 \\
\hline & 4 & 13.3 & 75.0 & 232 \\
\hline & 5 & 15.4 & 76.4 & 232 \\
\hline \multirow[t]{5}{*}{2} & 1 & 11.4 & 74.5 & 235 \\
\hline & 2 & 14.6 & 76.3 & 232 \\
\hline & 3 & 12.7 & 72.3 & 230 \\
\hline & 4 & 12.7 & 75.1 & 231 \\
\hline & 5 & 8.22 & 73.6 & 228 \\
\hline \multirow[t]{5}{*}{3} & 1 & 14.2 & 69.0 & 226 \\
\hline & 2 & 12.9 & 70.2 & 220 \\
\hline & 3 & 12.3 & 65.3 & 210 \\
\hline & 4 & 11.4 & 70.9 & 210 \\
\hline & 5 & 11.0 & 70.0 & 213 \\
\hline \multicolumn{2}{|c|}{ Mean 1} & 15.9 & 77.6 & 234 \\
\hline \multicolumn{2}{|c|}{ Mean 2} & 11.9 & 74.4 & 231 \\
\hline \multicolumn{2}{|c|}{ Mean 3} & 12.4 & 69.1 & 216 \\
\hline \multicolumn{2}{|c|}{ Overall mean } & 13.4 & 73.7 & 227 \\
\hline \multicolumn{2}{|c|}{ Intra-assay inaccuracy $1(\% \mathrm{dev})$} & 11.8 & 15.0 & -4.33 \\
\hline \multicolumn{2}{|c|}{ Intra-assay inaccuracy $2(\% \mathrm{dev})$} & -16.0 & 10.2 & -5.63 \\
\hline \multicolumn{2}{|c|}{ Intra-assay inaccuracy $3(\% \mathrm{dev})$} & -13.0 & 2.34 & -11.9 \\
\hline \multicolumn{2}{|c|}{ Interassay inaccuracy $(\% \mathrm{dev})$} & -5.72 & 9.16 & -7.29 \\
\hline \multicolumn{2}{|c|}{ Intra-assay precision $1(\% \mathrm{CV})$} & 11.6 & 3.70 & 2.06 \\
\hline \multicolumn{2}{|c|}{ Intra-assay precision $2(\% \mathrm{CV})$} & 19.8 & 2.03 & 1.12 \\
\hline \multicolumn{2}{|c|}{ Intra-assay precision $3(\% \mathrm{CV})$} & 10.3 & 3.21 & 3.25 \\
\hline \multicolumn{2}{|c|}{ Interassay precision $(\% \mathrm{CV})$} & 18.9 & 5.70 & 4.25 \\
\hline
\end{tabular}

dev deviation, $C V$ coefficient of variation

\section{DNA determination}

The fluorescent dye Hoechst 33258 selectively binds to double-stranded DNA, upon which the fluorescent signal and absorption wavelength shift [9]. Initially, we prepared Hoechst 33258 in assay buffer that was diluted ten times. This, however, resulted in slowly increasing fluorescence signals, which kept increasing for up to $5 \mathrm{~h}$ after addition. When we used undiluted assay buffer, on the other hand, the signal rapidly increased, allowing direct analysis. Others have reported that high salt concentrations dissociate the DNA from proteins in crude cell extracts [9]. Cell lysis was performed in a relatively large volume of water. When smaller volumes were used, cell numbers in samples with a high PBMC concentration were underestimated, indicating incomplete dissolution of the DNA. Finally, we noticed variation in the final measurement of the microplate. To reduce this variation, each well was measured five times.

\section{Method comparison}

We systematically compared the three methods described by applying each of them to PBMCs originating from four different individuals. The results of this comparison are presented in Fig. 2. With coefficients of variation lower than $10 \%$, all methods showed good precision. Moreover, high correlation coefficients were found between the cell number determined using the haemocytometer and the protein (0.959) and DNA-based results (0.995). The slightly lower coefficient of correlation for the protein determination was most likely caused by variable red blood cell contamination. In agreement with our preliminary experiments, the samples containing relatively high numbers of red blood cells showed a relatively high protein concentration, whereas the DNAbased method remained unaffected. The cell numbers determined using the DNA-based method deviated by 9.74-19.1\% from the numbers determined using the haemocytometer.

Table 2 Stability data of PBMC samples. Samples containing $67.5 \times 10^{6} \mathrm{PBMCs} / \mathrm{mL}$ were stored under analytically relevant conditions, after which the number of PBMCs was determined using the DNA-based counting method ( $N=3$ per condition)

\begin{tabular}{|c|c|c|c|c|c|}
\hline Matrix & Condition & $\begin{array}{l}\text { Nominal/initial concentration } \\
\left(10^{6} \mathrm{PBMCs} / \mathrm{mL}\right)\end{array}$ & $\begin{array}{l}\text { Measured concentration } \\
\left(10^{6} \mathrm{PBMCs} / \mathrm{mL}\right)\end{array}$ & CV (\%) & $\operatorname{Dev}(\%)$ \\
\hline PBS & $7 \mathrm{~h}$, ambient temperatures & 67.5 & 70.7 & 2.62 & 4.69 \\
\hline (non-lysed) & 2 freeze $\left(-70^{\circ} \mathrm{C}\right)$-thaw cycles & 67.5 & 74.1 & 6.08 & 9.78 \\
\hline Water & $2 \mathrm{~h}$, ambient temperatures & 67.5 & 73.2 & 0.993 & 8.52 \\
\hline (lysed) & 2 freeze $\left(-70^{\circ} \mathrm{C}\right)$-thaw cycles & 67.5 & 64.1 & 8.99 & -5.02 \\
\hline Reassay reproducibility & $\begin{array}{l}4.5 \mathrm{~h} \text {, ambient temperatures, } \\
\text { protected from light }\end{array}$ & 78.9 & 82.2 & 1.54 & 4.18 \\
\hline
\end{tabular}


Cell counting using a haemocytometer and cell counting using a microscope remain the reference methods. These methods, however, require intact cells and must therefore be performed before freezing the sample. Personnel trained for PBMC counting should thus be present when each sample is processed. Moreover, instruments and trained personnel should be available at each clinical site in the case of multicentre studies. A standardized assay performed in a central laboratory reduces the need for instruments and personnel, and the concomitant analytical variation. Of the two markers tested, DNA proved to be the most appropriate for PBMC counting. Therefore, we validated the DNAbased PBMC counting method.

DNA-based cell count validation

\section{Linearity}

The mean back-calculated deviations from the nominal concentrations of the calibration standards ranged from -6.75 to $3.35 \%$ and the precision was better than $10.4 \%$ at all calibration levels. The correlation coefficients were 0.993 or better.

Inaccuracy and precision

The assay performance is presented in Table 1. The determined mean PBMC concentrations deviated by -5.72 , 9.16 and $-7.29 \%$ from the nominal concentration for the validation samples containing $14.2 \times 10^{6}, 67.5 \times 10^{6}$ and $245 \times 10^{6} \mathrm{PBMCs} / \mathrm{mL}$, respectively. All precisions were lower than $15 \%$, except for the lowest validation sample, where it was lower than $20 \%$. In conclusion, both the inaccuracy and the precision of the method are satisfactory.

\section{Stability}

The stability of the samples under different conditions is summarized in Table 2. Deviations of less than $15 \%$ were found, showing that the samples were stable under all conditions tested. Long-term stability tests are ongoing.

\section{Summary}

The method described should also be applicable to other types of cells as long as the amount of DNA per cell is identical to that of PBMCs. Results obtained from leukaemic or other malignant cells should, thus, be interpreted with care because malignant cells often have an aberrant karyotype and thus contain an aberrant amount of DNA. Moreover, chemotherapeutic agents can cause a shift in the cell cycle of dividing cells, thereby altering the amount of DNA per cell. This is, however, not a problem for healthy PBMCs, which are non-dividing.

\section{Conclusions}

A DNA-based cell counting method is preferable over a protein-based method, because inevitable red blood cell contamination of PBMC samples severely influences the protein content. The DNA-based method described has been validated for the accurate and precise determination of the number of PBMCs present in a sample of isolated PBMCs. Crude cell suspensions could be used with minimal sample pretreatment, allowing fast analysis. The determination is not influenced by red blood cell contamination.

Acknowledgement The authors would like to thank Joke Schol for her excellent technical assistance.

Open Access This article is distributed under the terms of the Creative Commons Attribution Noncommercial License which permits any noncommercial use, distribution, and reproduction in any medium, provided the original author(s) and source are credited.

\section{References}

1. Rodriguez Orengo JF, Santana J, Febo I, Diaz C, Rodriguez JL, Garcia R, Font E, Rosario O (2000) P R Health Sci J 19: 19-27

2. King T, Bushman L, Kiser J, Anderson PL, Ray M, Delahunty T, Fletcher CV (2006) J Chromatogr B 843:147-156

3. Shi G, Wu JT, Li Y, Geleziunas R, Gallagher K, Emm T, Olah T, Unger S (2002) Rapid Commun Mass Spectrom 16:1092-1099

4. Benech H, Theodoro F, Herbet A, Page N, Schlemmer D, Pruvost A, Grassi J, Deverre JR (2004) Anal Biochem 330:172-174

5. Salmon-Ceron D, Lassalle R, Pruvost A, Benech H, Bouvier-Alias M, Payan C, Goujard C, Bonnet E, Zoulim F, Morlat P, Sogni P, Perusat S, Treluyer JM, Chene G (2003) Clin Infect Dis 36:12951304

6. Becher F, Pruvost A, Goujard C, Guerreiro C, Delfraissy JF, Grassi J, Benech H (2002) Rapid Commun Mass Spectrom 16:555-565

7. Veltkamp SA, Hillebrand MJ, Rosing H, Jansen RS, Wickremsinhe ER, Perkins EJ, Schellens JH, Beijnen JH (2006) J Mass Spectrom 41:1633-1642

8. Bradford MM (1976) Anal Biochem 72:248-254

9. Labarca C, Paigen K (1980) Anal Biochem 102:344-352 